\title{
Dim ultraviolet light as a means of deterring activity by the Hawaiian hoary bat Lasiurus cinereus semotus
}

\author{
P. Marcos Gorresen ${ }^{1, *}$, Paul M. Cryan ${ }^{2}$, David C. Dalton ${ }^{3}$, Sandy Wolf ${ }^{3}$, \\ Jessica A. Johnson ${ }^{1}$, Christopher M. Todd ${ }^{1}$, Frank J. Bonaccorso ${ }^{4}$ \\ ${ }^{1}$ Hawai'i Cooperative Studies Unit, University of Hawai'i at Hilo, Hilo, HI 96720, USA \\ ${ }^{2}$ Fort Collins Science Center, United States Geological Survey (USGS), Fort Collins, CO 80526, USA \\ ${ }^{3}$ Bat Research and Consulting, Tucson, AZ 85745, USA \\ ${ }^{4}$ Pacific Island Ecosystems Research Center, USGS, Hawai'i National Park, HI 96718, USA
}

\begin{abstract}
Widespread bat fatalities at industrial wind turbines are a conservation issue with the potential to inhibit efficient use of an abundant source of energy. Bat fatalities can be reduced by altering turbine operations, but such curtailment decreases turbine efficiency. If additional ways of reducing bat fatalities at wind turbines were available such tradeoffs might not be needed. Based on the facts that bats perceive distant objects primarily through vision and can see in very dim lighting conditions, and the possibility that bats might interact with turbines after approaching them as they would trees, we propose a novel method of reducing bat activity at wind turbines: illumination of the structure with dim light. As a first step toward assessing this approach, we illuminated trees with dim flickering ultraviolet (UV) light in areas frequented by Hawaiian hoary bats Lasiurus cinereus semotus, an endangered subspecies affected by wind turbines. We used a repeated-measures design to quantify bat activity near trees with acoustic detectors and thermal video cameras in the presence and absence of UV illumination, while concurrently monitoring insect numbers. Results indicate that dim UV reduces bat activity despite an increase in insect numbers. Experimental treatment did not completely inhibit bat activity near trees, nor did all measures of bat activity show statistically significant differences due to high variance in bat activity among sites. However, the observed decreases in bat activity with dim UV illumination justify further testing of this method as a means to reduce bat fatalities at wind turbines.
\end{abstract}

KEY WORDS: Chiroptera - Deterrence · Perception - Sensory ecology · Ultraviolet vision · Wildlife conservation

\section{INTRODUCTION}

Bats often fatally interact with industrial wind turbines. Prior to the late 1990s, bat fatalities resulting from collisions with human-made structures were uncommon (Cryan 2011), yet recent deployment of tall, monopole (single tube) wind turbines has resulted in unanticipated and unprecedented numbers of bat fatalities (Kunz et al. 2007, Arnett et al. 2008). Tens of

${ }^{*}$ Corresponding author: mgorresen@usgs.gov thousands of bat fatalities now occur each year at wind turbines in the USA and Canada (Arnett \& Baerwald 2013), and substantial numbers are also reported from Europe (Rydell et al. 2010a, Voigt et al. 2015).

Certain species of bats appear more susceptible to wind turbines than others. For example, of the 45 species that occur in the USA and Canada, only a few make up the majority ( $80 \%)$ of documented fatalities at turbines: hoary bats Lasiurus cinereus comprise

() The authors 2015. Open Access under Creative Commons by Attribution Licence. Use, distribution and reproduction are unrestricted. Authors and original publication must be credited.

Publisher: Inter-Research · www.int-res.com 
about $40 \%$, eastern red bats $L$. borealis about $25 \%$, and silver-haired bats Lasionycteris noctivagans about $20 \%$ (Arnett \& Baerwald 2013). A common characteristic of these species, and similar species experiencing fatality at turbines in Europe, is that they roost in trees throughout the year and are often referred to as 'tree bats' (Strelkov 1969, Cryan \& Barclay 2009). The underlying causes of their susceptibility to wind turbine fatalities remain unknown and hypotheses include coincidental causes (e.g. proximity to colonies, or random encounters during bat migration, including a possible link between turbine height and its interaction with insect migration and high-altitude feeding by bats; Rydell 2010b) and resource-based causes of attraction (e.g. bats seeking food, shelter, or social opportunities at turbines; Cryan \& Barclay 2009). Such resources may occur more often at trees and emergent, tree-like structures, and field observations from North America suggest that tree bats might approach turbines while seeking these resources (Horn et al. 2008, Cryan et al. 2014, Jameson \& Willis 2014). In Sweden, bats were observed attempting to land upon, roost within, socially display from, and forage from offshore wind turbines (Ahlén et al. 2009). Given the possibilities of tree bats using wind turbines as surrogate structures, methods of keeping bats away from turbines may reduce their fatality risk.

Vision is the primary means by which bats perceive distant objects and landscape features, and thus navigate and orient across large areas (Griffin 1970, Suthers 1970, Cryan \& Diehl 2009, Tsoar et al. 2011, Boonman et al. 2013). In addition to generally finding their way around landscapes at night, bats use vision and ambient light to locate roosts in trees (Ruczyński et al. 2011). Bats can see well in very dim ambinent light that appears dark to humans (Ellins \& Masterson 1974). However, under dim-light conditions tree bats may not be able to cognitively differentiate the visual silhouettes of trees from the cylindrical towers and branch-like blades of wind turbines (Cryan \& Brown 2007, Cryan 2008, Cryan et al. 2014).

Although early reports indicated no difference in bat fatalities between turbines lit with aviation safety lighting and those without (e.g. Arnett et al. 2008), a recent study from Texas reported significantly lower fatality rates of eastern red bats Lasiurus borealis, as well as approx. $50 \%$ fewer fatalities of hoary bats, at turbines lit with red flashing aviation lights (Bennett \& Hale 2014). This finding suggests that illuminating turbines, albeit in a spectrum of light near the edge of bat visual perception (Mistry \& McCracken 1990), may decrease the chances of tree bats approaching turbines and subsequent fatalities. As stated by
Cryan et al. (2014), 'supplemental lighting of turbines might make some bats less likely to mistake them for trees' (p. 15130). However, illuminating large areas of wind turbines with light that is visible to human observers may be unacceptable due to existing concerns about aviation safety, the visual conspicuousness of turbines at night, as well as the potential for disorienting and 'entrapping' nocturnally migrating birds (Longcore \& Rich 2004).

Recent investigation has shown that many bats can see ultraviolet (UV) light (e.g. Winter et al. 2003, Xuan et al. 2012, Gorresen et al. 2015). The eyes of some bats in the chiropteran suborder Yangochiroptera (formerly Microchiroptera) appear most sensitive to light intensities comparable to those available during crepuscular periods (Müller et al. 2009), and the adaptive advantages to seeing UV may include orientation by post-sunset glow, stars, and polarized light patterns in the sky (Childs \& Buchler 1981, Buchler \& Childs 1982, Greif et al. 2014). Insects, particularly moths, are also known to aggregate at lights rich in short-wavelengths (van Langevelde et al. 2011), and these aggregations may in turn attract foraging insectivorous bats (Blake et al. 1994, Rydell \& Racey 1995, Minnaar et al. 2014, Mathews et al. 2015).

Synthesizing these concepts, we propose that bat fatalities at wind turbines may be reduced by illuminating turbines with dim light visible to bats but not humans or birds. We reason that dim illumination will reduce visual contrast between wind turbines and lighter sky backgrounds, thereby decreasing visual similarities between the silhouettes of trees and wind turbines at night. As a first step toward testing this idea, we conducted a field experiment in which we illuminated trees with very dim UV light and compared activity of free-flying hoary bats and insects in the presence and absence of UV illumination. We included insect response in our study to assess the potential for confounding effects, that is, whether UV illumination attracted a sufficient number of nocturnal insects to subsequently attract bats. We present evidence that bat activity at the trees was reduced by dim lighting and propose that such illumination may be an effective method for dissuading bats from approaching wind turbines.

\section{MATERIALS AND METHODS}

This field study was conducted from 8 September through 16 October 2014 at a site situated 9 miles south of Hilo, Hawai'i Island, USA. At an elevation of 
about $230 \mathrm{~m}$, vegetation in the area consists of a plantation of approx. $5 \mathrm{~m}$ tall macadamia Macadamia integrifolia bordered by $40 \mathrm{~m}$ tall windbreaks of Cook's pine Araucaria columnaris. Previous observations by the authors (P. M. Gorresen \& F. J. Bonaccorso; Gorresen et al. 2013) confirmed relatively high levels of activity by Hawaiian hoary bats Lasiurus cinereus semotus in the area. In addition to belonging to the species found dead most frequently beneath wind turbines in continental North America (Arnett \& Baerwald 2013), L. C. semotus is the only species of bat occurring on the Hawaiian Islands, and this endangered subspecies has been found beneath wind turbines on multiple Hawaiian islands, making it an appropriate subject for this study.

The study consisted of a balanced design with replicate samples obtained at 10 sites within the plantation, located an average of $949 \mathrm{~m}$ apart. Each site was sampled both acoustically and with video cameras for 2 nights prior to treatment with UV illumination and these samples served as the experimental control. Each site was subsequently subject to experimental UV light treatment for 2 nights after the control sample. Samples at 2 sites (consisting of a control and a treatment) were run concurrently each night, and twenty nights of each type of observation resulted in a total of 40 sampling nights.

Each sample site was comprised of an open area situated between the macadamia trees and a linear windbreak of closely-spaced (5 m apart) Cook's pine trees onto which UV light was aimed during treatment nights (see Fig. S1 in the Supplement at www. int-res.com/articles/suppl/n028p249_supp.pdf). UV illumination was provided by 2 custom-made emitters spaced $30 \mathrm{~m}$ apart and angled $20^{\circ}$ horizontally from the between-emitter axis towards the windbreak and $30^{\circ}$ vertically relative to the horizon. UV illumination from each emitter was produced with a peak wavelength of $365 \mathrm{~nm}$ and a spectral spread of approximately $10 \mathrm{~nm}$ of light at full-width, halfmaximum (range: 335 to $395 \mathrm{~nm}$ ). Each emitter had a power density, at a distance of $30 \mathrm{~m}$, of approx. 1 microwatt $\mathrm{cm}^{-2}$ over a circular region of $20 \mathrm{~m}$ radius. This light level was determined during previous experimental trials to be sufficient to elicit a significant behavioral response in 7 species of bats representing 3 taxonomic families, and to demonstrate their capacity to see very dim UV light (Gorresen et al. 2015). Emitted UV light flickered randomly with a duty cycle of between 0.1 and $5 \mathrm{~s}$. All experimental protocols were approved by the Institutional Animal Care and Use Committee of the University of Hawai'i at Mānoa and the US Fish \& Wildlife Service.
Hawaiian hoary bat L. C. semotus (hereafter 'bat') activity at each control and treatment site was quantified both acoustically and visually. Bat echolocation was monitored with ultrasonic detectors (Song Meter 2 Bat+, Wildlife Acoustics), with microphones oriented towards the air-space imaged by video cameras. Bat occurrence was visually assessed using surveillance cameras equipped with $10 \mathrm{~mm}$ lenses (Axis Q1922-E, Axis Communications). These cameras image in the 'thermal' spectrum of infrared light (approx. 9000$14000 \mathrm{~nm}$ ) and require no supplemental illumination. At each sample site, a surveillance camera was set at the edge of the open area and aimed towards the airspace on the illuminated side of the windbreak of trees. Each camera's field of view at $50 \mathrm{~m}$ distance was approx. $54 \mathrm{~m}$ wide by $41 \mathrm{~m}$ high. Nightly measures of bat activity derived from video consisted of the total detections at mid-range $(\leq 50 \mathrm{~m})$ and near-range distances only ( $\leq 25 \mathrm{~m}$ ) to the camera, and 'duration' (total time in seconds of video detections adjusted by the sum of such nightly events). Video imagery was processed using custom-written code and matrixbased statistical software (Mathworks) to automatically detect animals flying through the video scenes (Fig. S2 in the Supplement). Video was recorded at 30 frames per second (fps), and every 10th video frame was analyzed, resulting in the detection of events lasting as little as $0.3 \mathrm{sec}$. All objects detected by software algorithms were visually reviewed and characterized as to identity and proximity. To assess whether lowintensity UV illumination affected available abundance of potential bat prey, insects were sampled nightly at each site with a Malaise trap (MegaView Science). Trapped insects were collected following each night of control/treatment sampling and dried in an oven for $48 \mathrm{~h}$ at $65^{\circ} \mathrm{C}$. Total number of insects per night was assessed by measuring dry weight biomass.

Bat and insect response to moon illumination, rainfall, temperature, and wind speed was also examined with a set of preliminary models to determine whether they should be considered for subsequent inclusion as additional fixed effects. Weather covariates were not significant predictors due to the low variability observed in the nightly values, and only moon illumination was retained in the models described below. Where UV treatment and moon illumination were each significantly associated with bat or insect response as main effects, they were also included in models as interaction effects. Moon illumination was recorded as the proportion of lunar disk illuminated; data were obtained from the Astronomical Applications Department of the US Naval Observatory (aa.usno.navy.mil/index.php). 
We tested the hypotheses that illuminating trees with dim ultraviolet light would cause localized changes in bat and insect activity. Bat and insect response to UV treatment and other covariates were obtained from repeated measures at 10 sites. These relationships were estimated using a generalized linear mixed effects model (GLMM) and by treating sampling site as a random factor. We implemented models within a Bayesian Monte Carlo Markov Chain (MCMC) framework using the package MCMCglmm (ver. 2.21; Hadfield 2010) in program R (ver. 3.1.0; R Development Core Team 2011). The continuous response variable 'duration' was logtransformed and 'insect biomass' was square-root transformed prior to modeling with a Gaussian error structure. All other response variables were count data for which a Poisson error structure was specified in the mixed model. Additional model fitting details are provided in the Supplement.

\section{RESULTS}

We recorded a total of 3768 echolocation passes during the study period, of which only $4 \%(n=143)$ consisted of terminal-phase call sequences indicative of feeding. We detected bats on video a total of 1164 times, about $58 \%(n=676)$ of which were observed at near range $(\leq 25 \mathrm{~m})$. The duration of video detections of bats totaled to $1930 \mathrm{~s}$ (32 $\mathrm{min}$ ) throughout the 40 nights sampled. Descriptive statistics of the response variables are presented in Table 1, Fig. 1, and Table S1 in the Supplement.

We observed statistically significant differences in the total number of echolocation passes detected between control and treatments, with detections declining by $44 \%$ from a mean of 41 per night without illumination to 23 per night with UV light treatment (Table 1, Fig. 1A). The duration of bat detections by video increased by $40 \%$ from an average of $1.5 \mathrm{~s}$ on control nights to $2.1 \mathrm{~s}$ on treatment nights (Fig. 1E). Treatment means were not statistically different from that of the control for all other measures of bat response; however, the apparent tendency for decreased bat activity near trees when they were lit with dim UV light was consistent among responses, with no contrary patterns evident.

We observed a significant 5-fold increase in insect biomass on nights with UV illumination (from a dry

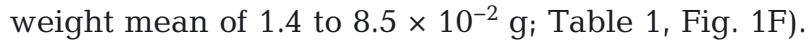
The response of bat occurrence and vocalization to the presence of insects (as measured by biomass) appeared to be negligible. Insects were never observed aggregating near the UV light emitters at night during the study. Almost all insects caught were moths in the 4 to $15 \mathrm{~mm}$ size range.

Moon illumination did not appear to affect bat occurrence as measured by video, but it was significantly associated with increased echolocation activity (Table 1). In bright moonlight, the average number of acoustic detections increased more than 3-fold for all echolocation passes (from a mean of 13 to 57) and about 10-fold for terminal phase calls (from a mean of 0.2 to 2.2). Moreover, the interaction between UV and moon illumination showed that acoustic activity on full-moon nights with UV was $60 \%$ lower than on full-moon nights without UV. In contrast, the interaction between UV and moon illumination demonstrated a 30-fold increase in insect biomass on new-moon nights that had received UV treatment relative to those nights without UV. Also, insect biomass during full-moon nights was significantly reduced, but similar between nights with and without UV treatment, indicating that the effects of UV diminished in brighter moonlight.

In general, the variance attributable to the random effect 'site' was high, particularly for those measures of bat activity derived from acoustic detections. The proportion of variance attributable to site-to-site differences, relative to residual (observation-level) variance, was $89 \%$ for all acoustic detections and $81 \%$ for the subset of terminal phase calls, whereas model variance was $58 \%$ and $63 \%$ for the video-derived response variables 'mid-range' and 'near-range', respectively. In comparison, site-to-site differences in insect biomass contributed only $1 \%$ to model variance.

\section{DISCUSSION}

Our findings tentatively suggest that dimly illuminating trees with flickering UV light affects bat behavior and decreases nearby activity. Experimental treatment of trees did not completely inhibit activity, nor did all measures of bat activity show statistically significant changes during illumination treatments. High among-site variability of observed bat detections likely contributed to low statistical power and the lack of significance in some of our tests. However, lack of statistical significance does not equate to a lack of biological effect. Overall, the direction and magnitude of the acoustic and video-derived measures of bat activity were consistent with the hypothesis that dim UV illumination leads to a general reduction in bat activity. The effect of UV illumination on reducing activity was particularly evident in the acoustic data, which com- 
Table 1. Summary results of Markov chain Monte Carlo (MCMC) generalized linear mixed models relating Hawaiian hoary bats Lasiurus cinereus semotus and insect response to the illumination of trees with dim ultraviolet (UV) light near Hilo, Hawai'i. Values shown include the posterior means of fixed effects, the lower and upper 95\% credible intervals (L95CI; U95CI), and the MCMC p-value for the estimate. Change is the percent difference of the posterior means of the fixed effect relative to the model intercept, with the exception that for the interaction models it also refers to the difference between the interaction effect of UV treatment and full moon illumination relative to that without UV treatment and no moon illumination. Posterior mean estimates are reported on their original scale (i.e. inverse link function applied). Fixed effects p-values significant at 0.05 are highlighted in bold

\begin{tabular}{|c|c|c|c|c|c|c|}
\hline Response variable & Parameter & Posterior & L95CI & U95CI & $\mathrm{p}$-value & Change (\%) \\
\hline \multirow{14}{*}{$\begin{array}{l}\text { Echolocation passes } \\
\text { (acoustic, counts) }\end{array}$} & Intercept & 30.23 & 8.41 & 104.48 & 0.001 & \\
\hline & Intercept & 40.67 & 11.63 & 151.74 & $<0.001$ & \\
\hline & UV & 22.96 & 6.41 & 82.47 & 0.007 & -44 \\
\hline & Intercept & 30.48 & 9.20 & 104.95 & $<0.001$ & \\
\hline & Insect & 27.39 & 7.95 & 95.85 & 0.342 & -10 \\
\hline & Intercept & 12.72 & 3.38 & 50.09 & 0.001 & \\
\hline & Moon & 57.09 & 15.85 & 190.55 & 0.015 & 349 \\
\hline & Intercept & 20.47 & 5.15 & 84.67 & 0.001 & \\
\hline & UV & 13.01 & 3.48 & 51.08 & 0.040 & -36 \\
\hline & Moon & 60.47 & 16.47 & 202.42 & 0.072 & 195 \\
\hline & Intercept & 14.53 & 3.50 & 60.22 & 0.001 & \\
\hline & UV & 19.17 & 4.80 & 72.75 & 0.509 & 32 \\
\hline & Moon & 73.39 & 21.04 & 238.02 & 0.012 & 405 \\
\hline & UV $\times$ Moon & 29.64 & 8.02 & 105.21 & 0.067 & 104 \\
\hline \multirow{7}{*}{$\begin{array}{l}\text { Terminal phase calls } \\
\text { (acoustic, counts) }\end{array}$} & Intercept & 0.86 & 0.16 & 3.55 & 0.886 & \\
\hline & Intercept & 1.05 & 0.20 & 4.68 & 0.864 & \\
\hline & UV & 0.68 & 0.14 & 3.35 & 0.314 & -35 \\
\hline & Intercept & 0.81 & 0.18 & 3.33 & 0.821 & \\
\hline & Insect & 0.55 & 0.10 & 2.72 & 0.221 & -32 \\
\hline & Intercept & 0.21 & 0.02 & 1.71 & 0.119 & \\
\hline & Moon & 2.21 & 0.41 & 10.93 & 0.051 & 970 \\
\hline \multirow{7}{*}{$\begin{array}{l}\text { Mid-range } \\
\text { (video, counts) }\end{array}$} & Intercept & 18.86 & 11.11 & 31.22 & $<0.001$ & \\
\hline & Intercept & 21.62 & 12.87 & 37.99 & $<0.001$ & \\
\hline & UV & 16.24 & 9.54 & 27.94 & 0.163 & -25 \\
\hline & Intercept & 18.85 & 11.50 & 31.86 & $<0.001$ & \\
\hline & Insect & 17.51 & 10.19 & 29.67 & 0.383 & -7 \\
\hline & Intercept & 20.62 & 9.97 & 42.90 & $<0.001$ & \\
\hline & Moon & 17.59 & 9.27 & 34.48 & 0.736 & -15 \\
\hline \multirow{7}{*}{$\begin{array}{l}\text { Near-range } \\
\text { (video, counts) }\end{array}$} & Intercept & 5.70 & 2.46 & 13.17 & $<0.001$ & \\
\hline & Intercept & 7.25 & 3.01 & 17.35 & 0.001 & \\
\hline & UV & 4.50 & 1.85 & 11.31 & 0.142 & -38 \\
\hline & Intercept & 5.70 & 2.46 & 13.14 & 0.002 & \\
\hline & Insect & 4.40 & 1.85 & 10.62 & 0.061 & -23 \\
\hline & Intercept & 5.47 & 1.71 & 18.04 & 0.007 & \\
\hline & Moon & 5.80 & 1.92 & 16.54 & 0.924 & 6 \\
\hline \multirow{7}{*}{$\begin{array}{l}\text { Duration } \\
\text { (video, seconds) }\end{array}$} & Intercept & 1.73 & 1.47 & 2.02 & $<0.001$ & \\
\hline & Intercept & 1.46 & 1.19 & 1.82 & 0.001 & \\
\hline & UV & 2.05 & 1.66 & 2.55 & 0.027 & 40 \\
\hline & Intercept & 1.73 & 1.48 & 2.03 & $<0.001$ & \\
\hline & Insect & 1.88 & 1.56 & 2.28 & 0.158 & 8 \\
\hline & Intercept & 1.71 & 1.25 & 2.28 & 0.001 & \\
\hline & Moon & 1.75 & 1.36 & 2.25 & 0.921 & 2 \\
\hline \multirow{12}{*}{$\begin{array}{l}\text { Insect biomass } \\
\left(\text { dry weight } \times 10^{-2} \mathrm{~g}\right)\end{array}$} & Intercept & 4.24 & 2.53 & 6.45 & $<0.001$ & \\
\hline & Intercept & 1.43 & 0.36 & 2.99 & $<0.001$ & \\
\hline & UV & 8.49 & 5.51 & 12.03 & $<0.001$ & 494 \\
\hline & Intercept & 8.31 & 4.23 & 13.63 & $<0.001$ & \\
\hline & Moon & 2.07 & 0.58 & 4.43 & 0.019 & -75 \\
\hline & Intercept & 3.84 & 1.45 & 7.37 & $<0.001$ & \\
\hline & UV & 13.03 & 8.38 & 18.79 & $<0.001$ & 239 \\
\hline & Moon & 0.46 & 0.00 & 1.72 & 0.014 & -88 \\
\hline & Intercept & 0.71 & 0.01 & 2.57 & 0.034 & \\
\hline & UV & 22.23 & 15.83 & 29.44 & $<0.001$ & 3033 \\
\hline & Moon & 2.06 & 0.75 & 4.06 & 0.258 & 190 \\
\hline & UV $\times$ Moon & 2.00 & 0.63 & 4.32 & $<0.001$ & 182 \\
\hline
\end{tabular}



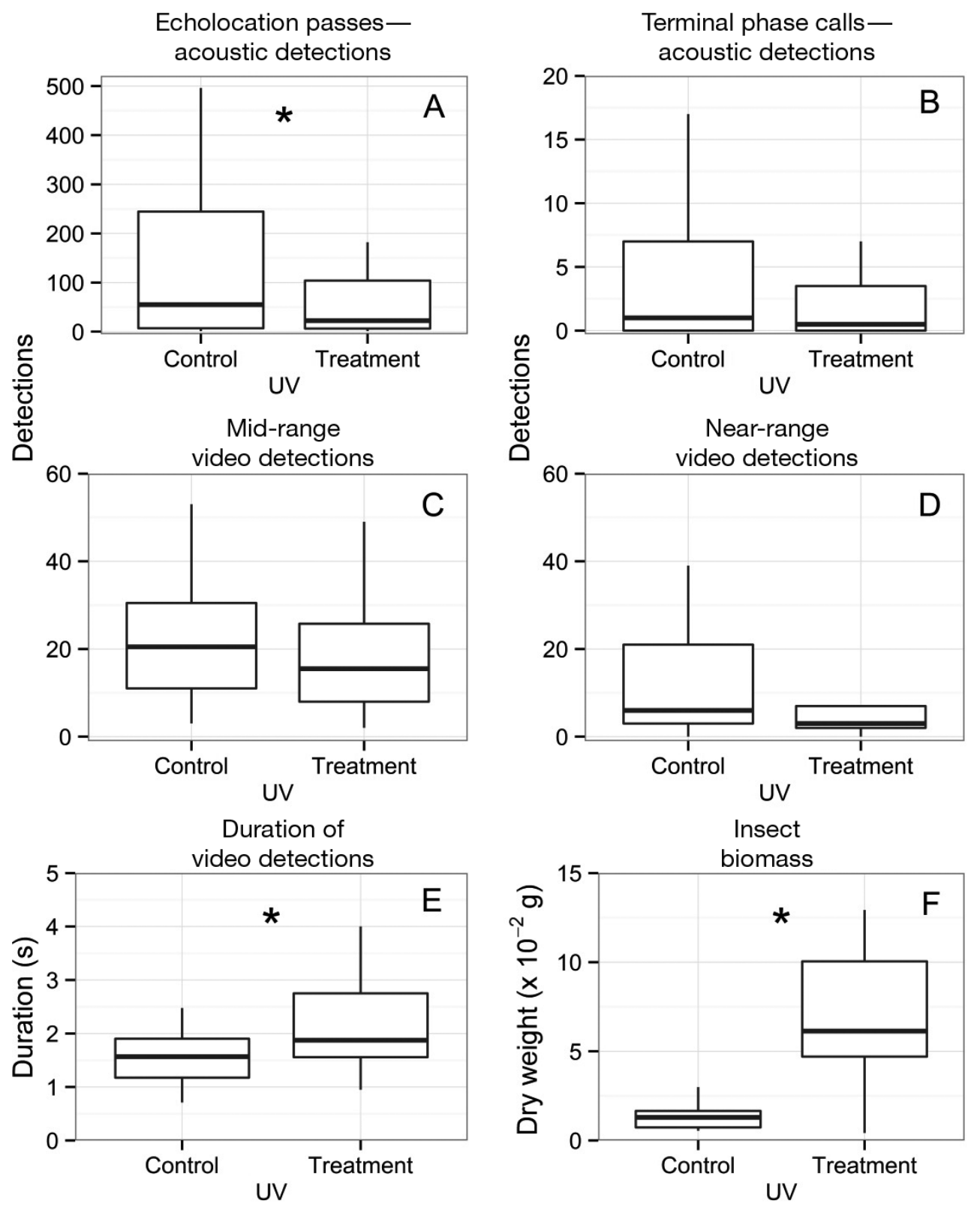

Fig. 1. Boxplots showing detections of Hawaiian hoary bats Lasiurus cinereus semotus and biomass of insects collected as a function of experimental control and treatment of trees with dim ultraviolet (UV) illumination near Hilo, Hawai'i. Bat acoustic detections comprise (A) nightly counts of all echolocation detections and (B) a subset that includes only terminal-phase (feeding) calls. Video detections include nightly counts made at (C) mid-range distances, (D) near-range distances, and (E) the mean duration (s) of all mid- and near-range detections. (F) Insect biomass is the mean nightly dry weight of insects captured in Malaise traps. Statistically significant differences for joint 2 night periods of treatment are denoted by asterisks (see Table 1). Boxplot whiskers denote values that lie within 1.5 times the interquartile range above the 75 th percentile and below the 25th percentile

prised the largest overall number of detections. A possible explanation for the difference between acoustic and video detections is that some bats may have stopped calling while still approaching trees illuminated with UV. Insectivorous bats sometimes stop echolocating during flight in complex acoustic environments (Chiu et al. 2008), and we speculate that they might also echolocate less frequently or even cease to echolocate when approaching visually unfamiliar objects (e.g. wind turbines; Cryan et al. 2014). Video also revealed that the mean duration of bat detections increased on nights with UV treatment. This result is consistent with the data showing fewer nearrange detections with UV treatment, indicating that 
bats avoided the area most illuminated by UV close to the camera, with the result that they would have been visible longer as they passed at farther distances across a wider field of view.

Insect biomass around trees clearly increased during treatment with UV illumination, and this apparent attraction ran counter to the pattern of Hawaiian hoary bat activity. Bat activity was not highly associated with insect abundance, and bats did not appear to have been drawn in by the insects attracted by UV illumination despite the fact that the samples were primarily comprised of moths in the size range used by Hawaiian hoary bats foraging in 'cluttered' habitats (Jacobs 1999). In general, insect abundance was relatively low even during UV treatment and we did not observe insects aggregating near the UV illuminators, suggesting that they were dispersed within the treated airspace to a degree that may not draw the attention of foraging bats.

Bat and insect activity showed disparate patterns as a function of moon illumination. Bat acoustic activity increased with moon illumination, whereas the biomass of captured insects decreased. The negative relationship of moonlight and insect activity has long been recognized (e.g. Williams \& Singh 1951). Some tropical non-insectivorous bat species also demonstrate moonlight avoidance (Saldaña-Vázquez \& Munguía-Rosas 2013), but temperate-zone insectivorous bats are not known to change activity patterns in any consistent way (Karlsson et al. 2002, Lima \& O'Keefe 2013). However, insectivorous bats may move among habitats as they exploit the shifting distributions of insects responding to changes in moonlight levels (Hecker \& Brigham 1999). Thus, higher bat acoustic activity may reflect greater availability of positively phototactic prey, or conversely, greater effort by bats foraging during periods of lower prey abundance. Any efforts to assess the effectiveness of using dim UV illumination to dissuade bats from approaching wind turbines should incorporate measures of ambient moonlight.

We very seldom observed birds at night in illuminated areas. This is an important finding, because not all animals flying through the airspace around wind turbines are equally susceptible to fatality at turbine blades, and there can be very large numbers of insects and birds flying above but not interacting with wind turbines at night (Cryan et al. 2014). Bats can see light at intensities lower than those at which the vision of humans and most birds function (Lythgoe 1979, Ellins \& Masterson 1974, Martin 1990), and dim artificial illumination may be a taxa-specific way to prevent bats from approaching tall structures.
Light at the intensity we used is unlikely to be perceived by most birds (some of which also see in UV; Withgott 2000). Although some nocturnal birds, such as owls and species in the family Caprimulgidae (e.g. nighthawks, nightjars and poorwills) have eyes approaching or equaling the light sensitivity of bats, there are no known cases of nocturnal birds that possess extreme low-light sensitivity at UV wavelengths (Ödeen \& Håstad 2003, Martin et al. 2004, Lind et al. 2014). We have little reason to believe that nocturnal birds would be attracted to dim UV illumination.

The ultimate goal of this research is to find a new way of reducing bat fatalities at wind turbines, yet this study was conducted at the base of trees. The reasons we illuminated trees instead of wind turbines for this initial effort included the potential link between bat susceptibility to turbines and the possibility of bats perceiving turbines as isolated or emergent trees (Ahlén et al. 2009, Cryan et al. 2014, Jameson \& Willis 2014), and the difficulty of deploying untested technology on operating wind turbines. However, elements of this study that may have limited the effectiveness of this technique include both the particular behaviors of Hawaiian hoary bats in the landscape where the study was conducted and the structures that were illuminated. Although hoary bats make seasonal altitudinal movements on Hawai'i Island (Gorresen et al. 2013), they are not known to make extensive migrations akin to those of their congeners, and fatalities at turbines in Hawaii do not show the distinct seasonal peak that they do in continental North America. The hoary bats flying around the lighted trees in this study were likely residents foraging in familiar territory (Bonaccorso et al. 2015). It is unknown if a bat's familiarity with landscape structures influences its interactions with them. We suspect that it might be harder to dissuade a resident bat from approaching a familiar structure in its usual foraging grounds than to dissuade a migrating bat from approaching an unfamiliar structure it briefly encounters during migration. Many of the bats we detected in this study were likely foraging in nearby habitats and not necessarily focusing their behaviors on the trees being illuminated, whereas migrating bats might approach wind turbines in a more directed and focused way (Horn et al. 2008, Ahlén et al. 2009, Cryan et al. 2014). Furthermore, wind turbines are also more prominent above the surrounding landscape than the trees of uniform height we studied. Dimly illuminating turbines in areas through which bats are migrating may better capture the attention of approaching bats than the experimental manipulations of tree windbreaks with UV light. 
We carried out this study by illuminating trees, which we believe were appropriate surrogate structures for wind turbines, but which are potentially much more difficult to treat with UV light. Plants absorb and reflect light at variable levels and our observations indicate that the trees we illuminated did not reflect much UV light. In addition to absorbing UV light, the multi-faceted needles of coniferous trees tend to scatter light rather than reflect it straight back toward a light source (Clark \& Lister 1975). We did not have instruments sensitive enough to measure the amount of UV light reflecting back from tree surfaces, but it was far below the reflected illumination intensity of 1 microwatt $\mathrm{cm}^{-2}$ by the time it reached the eyes of approaching bats. In contrast, most wind turbines have smooth metallic surfaces that are painted white or other light colors, which would reflect (and possibly fluoresce) considerably more UV light than tree surfaces. Furthermore, we were unable to illuminate trees so that their upper branches were optimally lit, which would be more feasible on wind turbines if lights were mounted above and below the nacelle (a machinery box to which rotors and blades attach) and pointed toward the blades and tower. Although we observed a general decrease in bat activity at dimly lit trees, we speculate that the greater reflectance and accessibility of elevated turbine surfaces could result in a similar or greater reduction in bat activity (if not offset by an increase in the number of insects attracted to UV).

Bat fatalities at turbines pose a considerable conservation problem. Existing methods of reducing bat fatalities such as turbine curtailment at low wind speeds can be costly and inefficient. Simple, effective, device-based solutions are needed. We speculate that tree bats approach wind turbines because they perceive them as trees, and that bats can be prevented from approaching by subtly lighting the wind turbines in ways that visually reduce such mistaken identity. Dimly illuminating the surfaces of wind turbines with light that is invisible to humans, yet visible to bats, may have potential to reduce bat activity and risk of fatality. We believe the patterns observed in this study warrant further investigation with other bat species and geographic settings, with particular attention given to the possibility of inadvertent adverse effects to non-target species.

Conflict of interest. The authors are involved in an effort to test dim, supplemental illumination as an effective method of preventing bats from flying toward and subsequently dying at wind turbines. The authors have a pending patent application which may be affected by the research reported in the enclosed paper. If the pending patents are granted and licensed for commercial development, some authors of this paper may be involved with that effort or benefit financially from it.

Acknowledgements. We thank D. Schell, Island Princess Macadamia Estate, for allowing us to carry out this study on this property. J. Rydell, K. Brinck and 2 anonymous reviewers provided helpful input on earlier drafts of the manuscript. Assistance with mechanical design and fabrication of the illuminators was provided by M. McCoy. Funding for this project was provided by the United States Geological Survey's Innovation Center for Earth Sciences and Ecosystems programs. We thank J. Stock and L. Allen for logistical support, K. Brinck for statistical advice, and Q. Gorresen for invaluable field assistance. Any use of trade, firm, or product names is for descriptive purposes only and does not imply endorsement by the US Government.

\section{LITERATURE CITED}

Ahlén I, Baagøe HJ, Bach L (2009) Behavior of Scandinavian bats during migration and foraging at sea. J Mammal 90: 1318-1323

Arnett EB, Baerwald EF (2013) Impacts of wind energy development on bats: implications for conservation. In: Adams RA, Pedersen SC (eds) Bat evolution, ecology, and conservation. Springer, New York, NY, p 435-456

Arnett EB, Brown WK, Erickson WP, Fiedler JK and others (2008) Patterns of bat fatalities at wind energy facilities in North America. J Wildl Manag 72:61-78

Bennett VJ, Hale AM (2014) Red aviation lights on wind turbines do not increase bat-turbine collisions. Anim Conserv 17:354-358

> Blake D, Hutson A, Racey P, Rydell J, Speakman J (1994) Use of lamplit roads by foraging bats in southern England. J Zool (Lond) 234:453-462

Bonaccorso FJ, Todd CM, Miles AC, Gorresen PM (2015) Foraging range movements of the endangered Hawaiian hoary bat, Lasiurus cinereus semotus (Chiroptera: Vespertilionidae). J Mammal 96:64-71

> Boonman A, Bar-On Y, Cvikel N, Yovel Y (2013) It's not black and white - on the range of vision and echolocation in echolocating bats. Front Physiol 4:248

$>$ Buchler ER, Childs SB (1982) Use of the post-sunset glow as an orientation cue by big brown bats (Eptesicus fuscus). J Mammal 63:243-247

Childs SB, Buchler ER (1981) Perception of simulated stars by Eptesicus fuscus (Vespertilionidae): a potential navigational mechanism. Anim Behav 29:1028-1035

Chiu C, Xian W, Moss CF (2008) Flying in silence: echolocating bats cease vocalizing to avoid sonar jamming. Proc Natl Acad Sci USA 105:13116-13121

Clark JB, Lister GR (1975) Photosynthetic action spectra of trees II. The relationship of cuticle structure to the visible and ultraviolet spectral properties of needles from four coniferous species. Plant Physiol 55:407-413

- Cryan PM (2008) Mating behavior as a possible cause of bat fatalities at wind turbines. J Wildl Manag 72:845-849

Cryan PM (2011) Wind turbines as landscape impediments to the migratory connectivity of bats. Environ Law 41: $355-370$ 
Cryan PM, Barclay RMR (2009) Causes of bat fatalities at wind turbines: hypotheses and predictions. J Mammal 90:1330-1340

Cryan PM, Brown AC (2007) Migration of bats past a remote island offers clues toward the problem of bat fatalities at wind turbines. Biol Conserv 139:1-11

Cryan PM, Diehl RH (2009) Analyzing bat migration. In: Kunz TH, Parsons S (eds) Ecological and behavioral methods for the study of bats. Johns Hopkins University Press, Baltimore, MD, p 477-488

Cryan PM, Gorresen PM, Hein CD, Schirmacher MR and others (2014) Behavior of bats at wind turbines. Proc Natl Acad Sci USA 111:15126-15131

Ellins SR, Masterson FA (1974) Brightness discrimination thresholds in the bat, Eptesicus fuscus. Brain Behav Evol 9:248-263

Gorresen PM, Bonaccorso FJ, Pinzari CA, Todd CM, Montoya-Aiona K, Brinck K (2013) A five-year study of Hawaiian hoary bat (Lasiurus cinereus semotus) occupancy on the island of Hawai'i. Hawai'i Cooperative Studies Unit, Tech Rep 41, University of Hawai'i at Hilo, HI

Gorresen PM, Cryan PM, Dalton D, Wolf S, Bonaccorso FJ (2015) Ultraviolet vision may be widespread in bats. Acta Chiropt 17:193-198

Greif S, Borissov I, Yovel Y, Holland RA (2014) A functional role of the sky's polarization pattern for orientation in the greater mouse-eared bat. Nat Commun 5:4488

Griffin DR (1970) Migration and homing of bats. In: Wimsatt WA (ed) Biology of bats, Vol 1. Academic Press, New York, NY, p 233-264

> Hadfield JD (2010) MCMC methods for multi-response generalised linear mixed models: the MCMCglmm R package. J Stat Softw 33:1-22

Hecker KR, Brigham RM (1999) Does moonlight change vertical stratification of activity by forest-dwelling insectivorous bats? J Mammal 80:1196-1201

Horn JW, Arnett EB, Kunz TH (2008) Behavioral responses of bats to operating wind turbines. J Wildl Manag 72: 123-132

Jacobs DS (1999) The diet of the insectivorous Hawaiian hoary bat (Lasiurus cinereus semotus). Can J Zool 77: 1603-1607

- Jameson JW, Willis CKR (2014) Activity of tree bats at anthropogenic tall structures: implications for mortality of bats at wind turbines. Anim Behav 97:145-152

Karlsson BL, Eklöf J, Rydell J (2002) No lunar phobia in swarming insectivorous bats (family Vespertilionidae). J Zool (Lond) 256:473-477

Kunz TH, Arnett EB, Erickson WP, Hoar AR and others (2007) Ecological impacts of wind energy development on bats: questions, research needs, and hypotheses. Front Ecol Environ 5:315-324

Lima SL, O'Keefe JM (2013) Do predators influence the behaviour of bats? Biol Rev Camb Philos Soc 88:626-644

Lind O, Mitkus M, Olsson P, Kelber A (2014) Ultraviolet vision in birds: the importance of transparent eye media. Proc R Soc B 281:20132209

Longcore T, Rich C (2004) Ecological light pollution. Front Ecol Environ 2:191-198

Lythgoe JN (1979) The ecology of vision. Clarendon Press, Oxford

Martin GR (1990) Birds by night. T \& AD Poyser, London

Martin G, Rojas LM, Ramírez Y, McNeil R (2004) The eyes of oilbirds (Steatornis caripensis): pushing the limits of sen- sitivity. Naturwissenschaften 91:26-29

Mathews F, Roche N, Aughney T, Jones N, Day J, Baker J, Langton S (2015) Barriers and benefits: implications of artificial night-lighting for the distribution of common bats in Britain and Ireland. Philos Trans R Soc Lond B 370:20140124

Minnaar C, Boyles JG, Minnaar IA, Sole CL, McKechnie AE (2014) Stacking the odds: light pollution may shift the balance in an ancient predator-prey arms race. J Appl Ecol 52:522-531

Mistry S, McCracken GF (1990) Behavioural response of the Mexican free-tailed bat, Tadarida brasiliensis, to visible and infra-red light. Anim Behav 39:598-599

Müller B, Glösmann M, Peichl L, Knop GC, Hagemann C, Ammermüller J (2009) Bat eyes have ultraviolet-sensitive cone photoreceptors. PLoS ONE 4:e6390

Ödeen A, Håstad O (2003) Complex distribution of avian color vision systems revealed by sequencing the SWS1 opsin from total DNA. Mol Biol Evol 20:855-861

R Development Core Team (2011) R: a language and environment for statistical computing. R Foundation for Statistical Computing, Vienna

Ruczyński I, Szarlik A, Siemers BM (2011) Conspicuous visual cues can help bats to find tree cavities. Acta Chiropt 13:385-389

Rydell J, Racey PA (1995) Streetlamps and the feeding ecology of insectivorous bats. Symp Zool Soc Lond 67: 291-307

Rydell J, Bach L, Dubourg-Savage MJ, Green M, Rodrigues L, Hedenström A (2010a) Bat mortality at wind turbines in northwestern Europe. Acta Chiropt 12:261-274

Rydell J, Bach L, Dubourg-Savage MJ, Green M, Rodrigues L, Hedenström A (2010b) Mortality of bats at wind turbines links to nocturnal insect migration? Eur J Wildl Res 56:823-827

Saldaña-Vázquez RA, Munguía-Rosas MA (2013) Lunar phobia in bats and its ecological correlates: a metaanalysis. Mamm Biol 78:216-219

Strelkov PP (1969) Migratory and stationary bats (Chiroptera) of the European part of the Soviet Union. Acta Zool Cracov 14:393-440

Suthers RA (1970) Vision, olfaction, taste. In: Wimsatt WA (ed) Biology of bats, Vol 2. Academic Press, New York, NY, p 265-309

Tsoar A, Nathan R, Bartan Y, Vyssotski A, Dell'Omo G, Ulanovsky N (2011) Large-scale navigational map in a mammal. Proc Natl Acad Sci USA 108:E718-E724

van Langevelde F, Ettema JA, Donners M, WallisDeVries MF, Groenendijk D (2011) Effect of spectral composition of artificial light on the attraction of moths. Biol Conserv 144:2274-2281

Voigt CC, Lehnert LS, Petersons G, Adorf F, Bach L (2015) Wildlife and renewable energy: German politics cross migratory bats. Eur J Wildl Res 61:213-219

Williams CB, Singh BP (1951) Effect of moonlight on insect activity. Nature 167:853

Winter Y, López J, Helversen OV (2003) Ultraviolet vision in a bat. Nature 425:612-614

Withgott J (2000) Taking a bird's-eye view... in the UV. Recent studies reveal a surprising new picture of how birds see the world. Bioscience 50:854-859

Xuan F, Hu K, Zhu T, Racey P, Wang X, Sun Y (2012) Behavioral evidence for cone-based ultraviolet vision in divergent bat species and implications for its evolution. Zoologia 29:109-114 